\title{
Experience with Canada's First Policy on Concussion Education and Management in Schools
}

\author{
Laureen D. Hachem, George Kourtis, Swapna Mylabathula, Charles H. Tator
}

\begin{abstract}
Background: In response to the rising incidence of concussions among children and adolescents, the province of Ontario recently introduced the Ontario Policy/Program Memorandum on Concussions (PPM No. 158) requiring school boards to develop a concussion protocol. As this is the first policy of its kind in Canada, the impact of the PPM is not yet known. Methods: An electronic survey was sent to all high school principals in the Toronto District School Board 1 year after announcement of the PPM. Questions covered extent of student, parent, and staff concussion education along with concussion management protocols. Results: Of 109 high school principals contacted, 39 responded $(36 \%)$. Almost all schools provided concussion education to students (92\%), with most education delivered through physical education classes. Nearly all schools had return to play (92\%) and return to learn (77\%) protocols. Although $85 \%$ of schools educated staff on concussions, training was aimed at individuals involved in sports/physical education. Only $43.6 \%$ of schools delivered concussion education to parents, and many principals requested additional resources in this area. Conclusions: One year after announcement of the PPM, high schools in the Toronto District School Board implemented significant student concussion education programs and management protocols. Staff training and parent education required further development. A series of recommendations are provided to aid in future concussion policy development.
\end{abstract}

RÉSUMÉ: Politique en matière de gestion des commotions cérébrales et de formation : l'expérience pionnière d'écoles secondaires canadiennes. Contexte: En réponse à l'incidence croissante de commotions cérébrales chez les enfants et les adolescents, le gouvernement ontarien a récemment fait paraitre une note (Politiques des Conseils scolaires sur les commotions cérébrales, No 158) exigeant de ces conseils qu'ils élaborent un protocole en matière de gestion des commotions cérébrales. L'impact d'une telle note demeure toutefois inconnu dans la mesure où il s'agit de la première initiative de ce genre au Canada. Méthodes: Une année après l'annonce de cette politique gouvernementale, nous avons envoyé un questionnaire électronique à toutes les directions d'établissements secondaires du Conseil scolaire du district de Toronto. Nos questions ont abordé l'étendue de la formation donnée aux élèves, aux parents et au personnel en ce qui concerne les commotions cérébrales et les protocoles de gestion de ces mêmes commotions. Résultats: Des 109 directeurs ou directrices ayant été contactés, 39 ont répondu au questionnaire (36\%). Presque toutes les écoles (92\%) avaient offert à leurs élèves une formation concernant les commotions cérébrales, la plupart d'entre elles le faisant dans le cadre de leurs cours d'éducation physique. De plus, presque toutes les écoles pouvaient compter sur des protocoles de retour au jeu (92\%) et de retour en classe (77\%). Bien que $85 \%$ des écoles ayant répondu au questionnaire veillaient à former leur personnel en ce qui a trait aux commotions cérébrales, l'offre de formation était destinée avant tout aux membres du personnel actifs dans les sports et en éducation physique. Seulement $43,6 \%$ des écoles avaient offert aux parents de la formation concernant les commotions cérébrales, de nombreux directeurs et directrices ayant demandé des ressources additionnelles à ce chapitre. Conclusions: Une année après le lancement de cette politique gouvernementale, on peut dire que les établissements secondaires de Conseil scolaire du district de Toronto ont mis sur pied des programmes de formation et des protocoles de gestion des commotions cérébrales notables. Cela dit, tant la formation du personnel que celle des parents devraient être améliorées. À cet égard, nous avons fourni une série de recommandations qui pourront, dans l'avenir, constituer un apport dans l'élaboration de politiques en matière de gestion des commotions cérébrales.

Key words: Brain injury, Brain injury - traumatic, Education, Head trauma

doi:10.1017/cjn.2016.41

Can J Neurol Sci. 2016; 43: 554-560

Concussions are the most common type of sports-related brain injury. Approximately 300,000 sports-related concussions occur annually in the United States and 100,000 in Canada; however, these numbers are likely a gross underestimate of the true incidence because many concussions go undiagnosed. ${ }^{1,2}$
Adolescents aged 13 to 19 years are at highest risk of sustaining a concussion because of the increased susceptibility to injury of the developing brain and the rising number of student athletes involved in sports activities each year. ${ }^{2-4}$ In addition to time away from school and athletic activities, concussions can lead to

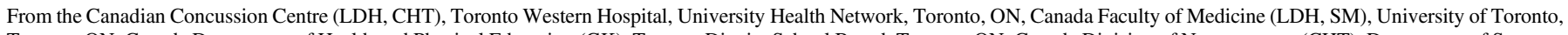

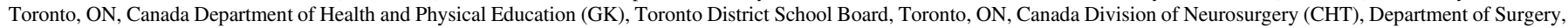
University of Toronto, Toronto, ON, Canada.

Received August 26, 2015. Final Revisions Submitted January 20, 2016. Date of Acceptance February 1, 2016.

Correspondence to: Charles H. Tator, University of Toronto, Division of Neurosurgery, Toronto Western Hospital, 399 Bathurst St. Room 4W-422, Toronto, ON M5T 2S8, Canada.

Email: charles.tator@uhn.ca 
significant long-term health sequelae and permanent brain damage if not properly managed. ${ }^{5}$ Given the high incidence and significant morbidity of these brain injuries, strategies to prevent and properly manage concussions in student athletes are now a public health priority. Implementation of student and parent concussion education, school management guidelines, and staff training on concussions are essential steps in primary and secondary prevention of concussions. ${ }^{6}$

All American states have enacted some form of concussion legislation requiring the institution of concussion management guidelines and education programs aimed at students, parents, and coaches. ${ }^{7-11}$ Although preliminary studies have found legislation effective at establishing concussion management protocols in schools and sports leagues, significant gaps remain in concussion education. ${ }^{12-14}$ In contrast to the United States, no province or territory in Canada has enacted official concussion legislation. In March 2014, the Ontario Ministry of Education made the first step toward an organized concussion plan through announcement of the Ontario Policy/Program Memorandum on Concussions (PPM No. 158). Under the PPM, school boards were required to develop a policy to prevent and appropriately manage concussions, to be implemented by January $30,2015 .{ }^{15}$ School boards were provided with various resources along with a minimum standard concussion protocol to aid in development of their policy to be implemented by all elementary, middle, and high schools in each board. However, it is not known how schools have implemented concussion policies since the announcement of the PPM and what barriers, if any, were faced during the process. Furthermore, because the PPM is not official legislation, it is important to evaluate whether Ontario's approach is adequate for enhancing concussion policies in schools or whether additional steps must be taken.

We therefore examined the extent of concussion policy implementation 1 year after announcement of the PPM in a sample of Ontario high schools. We focused on one school board, the Toronto District School Board (TDSB) because it is the largest board in Ontario. There were three primary objectives: (1) examine the extent of student and parent education, school management protocols, and staff training on concussions after introduction of PPM No. 158; (2) assess how high school concussion policies have changed compared with before introduction of the PPM; and (3) evaluate principals' opinions on the utility and impact of the PPM and the resources provided. From this analysis, we identified a number of important gaps in concussion education delivery and present here recommendations for school boards and all stakeholders involved in concussion education, management, and prevention.

\section{MeTHODS}

\section{Study Participants and Procedure}

Approval for this study was obtained from the University of Toronto Research Ethics Board and the Toronto District School Board External Research Review Committee. All high school principals in the TDSB $(n=109)$ were contacted by email on February 3, 2015 (the second business day after the deadline for school boards to implement their concussion policy). Principals were asked to complete an online 29-question survey on their school's concussion education programs and management protocols. All responses were anonymous because no identifying data was collected. Surveys were completed from February 3 to March 3, 2015, and two email reminders were sent.

\section{Instruments}

The 29-question electronic survey was developed to assess concussion education and management protocols in schools after implementation of the PPM (Appendix A). Respondents were asked about the extent of student and parent concussion education, school concussion management protocols, and staff training on concussions as of January 30, 2015. Respondents were also retrospectively asked about these four parameters before January 30, 2015. In addition, the survey assessed the respondent's perceptions about the PPM and familiarity with different concussion resources. The survey included questions adapted from previously validated surveys ${ }^{12,14}$ along with questions developed for the purposes of this study. The survey was validated by a member of the Health and Physical Education/Athletics Department at the TDSB because this department was mainly involved in developing and distributing the TDSB concussion education programs and protocols. Also, high school principals in another Ontario school board were consulted about the scope of the questions that could be answered by school principals.

\section{Data Analysis}

Survey responses were collected and descriptive statistics were generated for all variables. Categorical variables were expressed as percentages. To compare the change in concussion policy implementation in schools before and after the PPM, the McNemar test for paired proportions was used. All analyses were done using SAS (SAS Institute Inc.) software and a $\mathrm{p}$ value of $<0.05$ was taken to be significant.

\section{Results}

Of 109 high school principals contacted, 39 completed the survey for a response rate of $36 \%$. Among the schools that responded, $43.6 \%$ had more than 1000 students. Thirty-two of the schools that responded $(81 \%)$ had at least one documented

Table 1: Characteristics of responding schools $(n=39)$

\begin{tabular}{l|c|c}
\hline & No. of Schools & Percent \\
\hline School size (no. of students) & 17 & 43.6 \\
\hline$>1000$ & 11 & 28.2 \\
\hline $800-1000$ & 3 & 7.7 \\
\hline $600-800$ & 8 & 20.5 \\
\hline$<600$ & & 20.5 \\
\hline Number of concussions last year & 8 & 12.8 \\
\hline$>10$ & 5 & 38.5 \\
\hline $5-10$ & 15 & 10.3 \\
\hline $2-5$ & 4 & 12.8 \\
\hline 1 & 5 & 5.1 \\
\hline None & 2 & \\
\hline Don't know & & \\
\hline
\end{tabular}



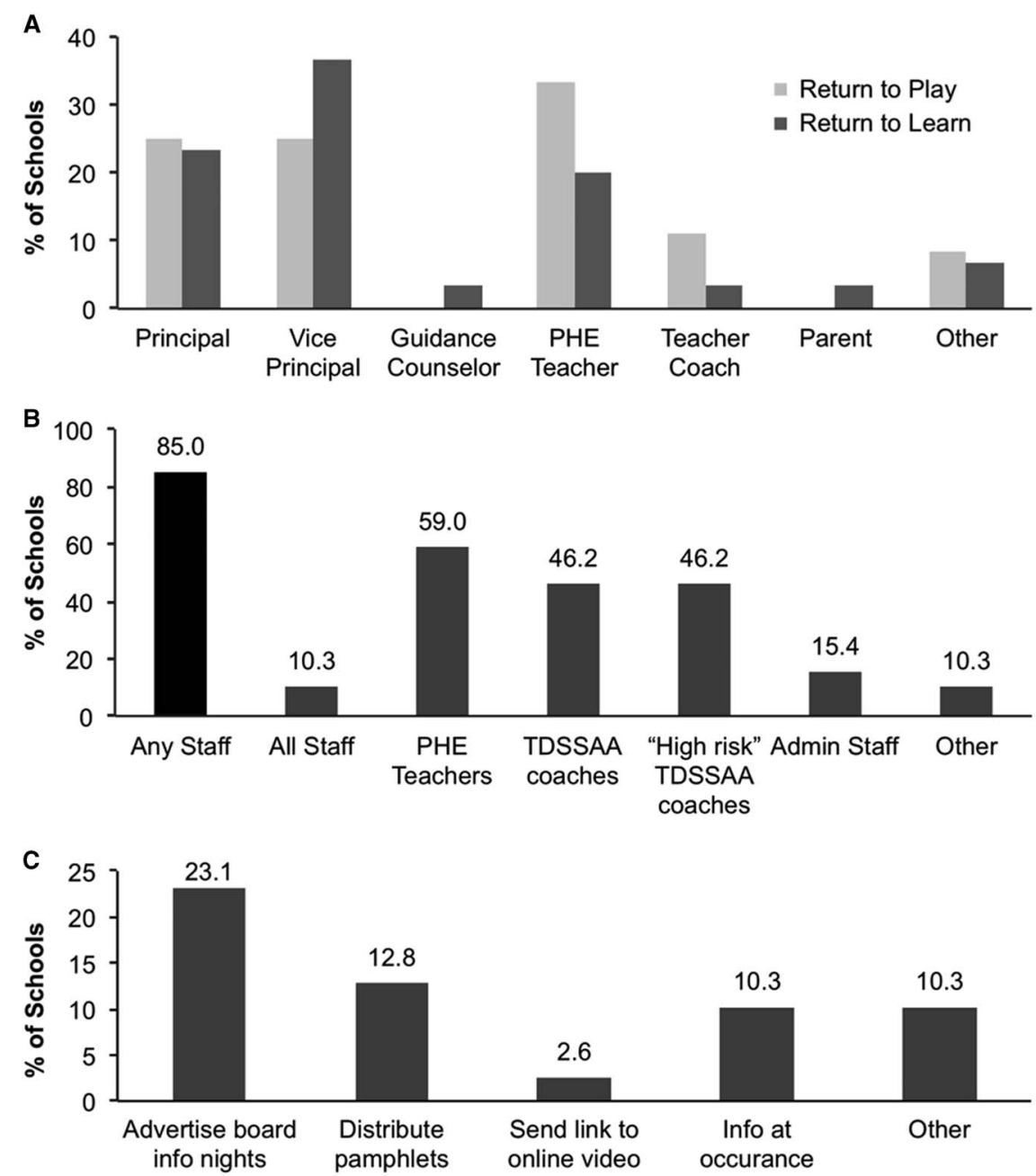

Figure 1: Details of school concussion management protocols and staff training and parent education in responding schools $(n=39)$. (A) Individuals currently in charge of return to play and learn protocols in schools. (B) Staff that receive concussion training. (C) Current means by which parents receive concussion education in Toronto District School Board high schools. $P H E=$ Physical and health education $;$ TDSSAA = Toronto District Secondary Schools Athletic Association.

concussion incident the previous year, and eight schools $(20.5 \%)$ had more than ten incidents (Table 1). In general, the higher number of concussions was seen among larger schools. A total of $95 \%$ of respondents said they were informed of the PPM before this study.

\section{Student Concussion Education}

As of January 30, 2015, some form of student concussion education was present in $92.3 \%$ of the TDSB high schools that responded to the survey. The majority of this education was being delivered in physical/health education (PHE) classes $(87.2 \%$ of schools), which all students are required to take in grade nine. Approximately one-half of schools (53.8\%) provided concussion education to students involved in an organized sports team (run through the Toronto District Secondary Schools Athletics Association); however, most of these schools also delivered education in PHE classes. As part of their student concussion education program, the majority of schools included education on the importance of following return to play (77\%) and return to learn $(64 \%)$ guidelines.

\section{School Concussion Management Protocols}

Only $56 \%$ of schools had a formal system to track the incidence of concussions, although many principals mentioned that they were in the process of developing such a system. Ninety-two percent of schools had a return to play protocol in place and $77 \%$ had a return to learn protocol. There was significant variability between schools in terms of the individuals in charge of the return to play and learn protocols as indicated in Figure 1A. For managing the return to play protocol, the responsibility was placed on either the principal, vice principal, or PHE teacher. A similar trend was seen in the individuals responsible for the return to learn protocol, with more schools placing the responsibility on the vice principal rather than the PHE teacher. Approximately $20 \%$ of principals reported that a PHE teacher was in charge of managing return to learn protocols at their school. 


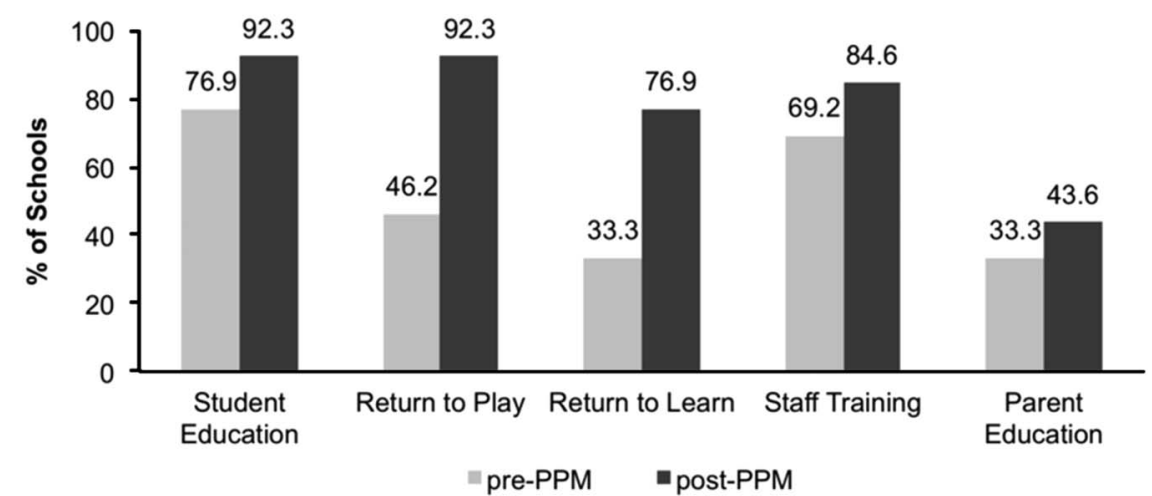

Figure 2: Comparison of school concussion policies before and after the PPM in 39 schools. PPM = Ontario Policy/Program Memorandum on Concussions.

\section{Staff Concussion Training}

Eight-five percent of schools trained staff on concussions; however, the majority of this training was directed toward PHE teachers or teacher-coaches (Figure 1B). Only $15.4 \%$ of schools reported training school administration staff and $10 \%$ provided general concussion education to all staff. Only $23 \%$ of principals were aware of the Parachute Canada Online Concussion Education Course, which is available for staff to obtain concussion training.

\section{Parent Concussion Education}

Only $44 \%$ of schools reported having a system in place to educate parents on concussions. A total of $23.1 \%$ of respondents actively advertised Board-Wide Concussion Education nights for parents to attend; however, many principals noted attendance at these events has been low. Although concussion education pamphlets and online videos are freely available from injury prevention organizations such as Parachute Canada, these resources were not being heavily used by schools to educate parents on concussions (Figure 1C).

\section{Comparison of Pre- versus Post-PPM Policies}

The comparison of different components of school concussion policies pre- versus post- PPM are provided in Figure 2. We found a significant increase in student education $(\mathrm{p}=0.03)$, staff training $(\mathrm{p}=0.03)$, return to play $(\mathrm{p}<0.0001)$, and return to learn $(\mathrm{p}<0.0001)$ management protocols, but parent education was not significantly changed. To test the robustness of our primary analysis, we conducted a sensitivity analysis whereby we reversed our initial assumption that schools who answered "I don't know" did not have the element in their previous policy and instead assumed that schools unaware of a specific aspect of their previous policy did in fact have that element in place before the PPM. With this analysis, student education and staff training were no longer significantly different pre- versus post-PPM, though differences in return to play and return to learn protocols remained significant.

\section{Needs Assessment and Principals' Perceptions on the PPM}

Of the resources available to schools for establishing concussion education and management protocols, the Ontario Physical and Health Education Association guidelines were the most wellknown (84.6\% of principals). The TDSB Grade 9 Concussion Program, a teaching resource recently created by the TDSB and distributed to schools to aid teachers in educating students on concussions, had a high awareness among principals (62\%). Very few principals were aware of the resources available through injury prevention and sports organizations such as Parachute Canada (20.5\%) and the Coaching Association of Canada (12.8\%) (Figure 3A).

Overall, $50 \%$ of principals wanted additional resources to help implement student education programs and concussion management protocols (Figure 3B). A higher proportion of principals desired additional resources to aid in delivering staff training $(69 \%)$ and parent education (82\%). In terms of principals' views on the PPM, 54\% either agreed or strongly agreed with the statement "The PPM on concussions has helped improve student education on concussions," whereas only $26 \%$ were neutral and $10 \%$ disagreed or strongly disagreed. Furthermore, $61 \%$ agreed or strongly agreed that "The PPM on concussions has helped students suffering symptoms of a concussion to receive the appropriate accommodations to meet their learning goals." Twenty-one percent were neutral and $18 \%$ disagreed or strongly disagreed with this statement. Several challenges and suggestions for implementing concussion education and raising awareness in schools were identified by principals (Table 2).

\section{Discussion}

This is the only study to date to formally evaluate concussion education and management protocols in Canadian high schools, and the first to examine the effect of the recent PPM on school concussion policies in Ontario.

In our survey of high school principals within the TDSB, nearly all respondents reported having student education programs in place at their school 1 year after announcement of the Ontario PPM. Most of this education was provided through grade nine PHE classes, which is a good avenue for delivery because PHE is mandatory for all grade nine students. However, schools should also consider ways to familiarize new students who transfer to a school after grade nine with the school's specific concussion protocol.

In addition, almost all schools had a return to play and learn protocol at the time of the survey. Interestingly, several schools 

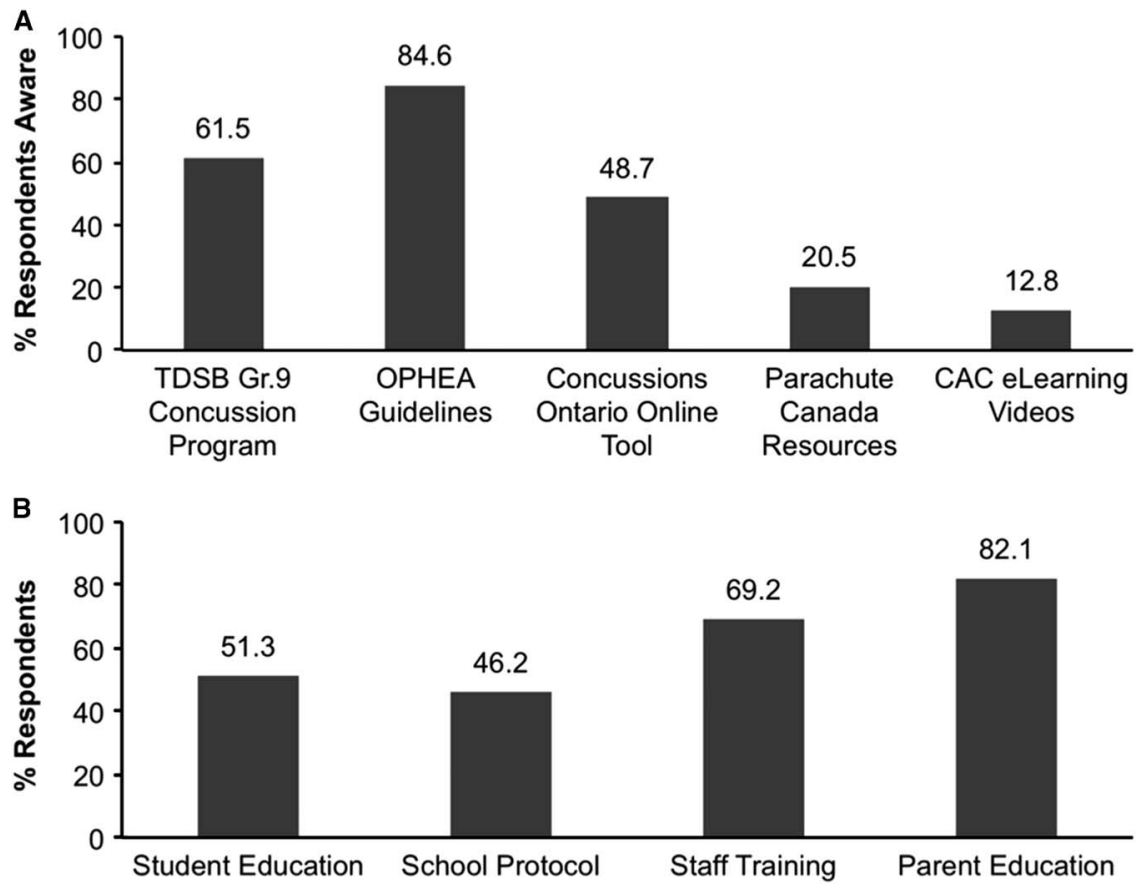

Figure 3: Principals' awareness and perceptions on concussion resources $(n=39)$. (A) Principals' awareness of concussion resources. (B) Aspects of school concussion policies that principals identified as requiring additional resources. CAC $=$ Coaching Association of Canada; OPHEA = Ontario Physical and Health Education Association; TDSB =Toronto District School Board.

were placing the responsibility for the return to learn protocol on physical education teachers. This responsibility should be placed on the principal or vice principal because these individuals have more oversight of a student's school life and are thus better able to organize any necessary accommodations. Although this point is not explicitly stated in the PPM, schools must be aware of the importance of designating appropriate staff to manage different aspects of their concussion guidelines. One solution to address this issue is the formation of a school committee dedicated to concussion-related issues containing representation from the school principal, PHE teachers, teacher-coaches, school administration, parents, and students. The committee would provide a forum to discuss the incidence and management of concussions in the school and raise any issues or necessary changes to school concussion policies.

Although a large portion of schools reported providing staff with concussion education, most training remains focused on individuals directly involved in sports or physical education and several principals stressed that they would like mandatory concussion training for all staff. The importance of universal staff training is underscored by the fact that many schools put the responsibility for concussion management on different categories of staff. Although not specifically asked in our survey, we know from our experience that, in many cases, school secretaries or administration staff members are involved in triaging a concussed student because they are often the first person to see a student admitted to the school office after an injury. Moreover, a surprisingly high number of principals were unaware of the Parachute Canada Staff Training Videos. We suspect that the cost associated with this course has limited its widespread distribution within school boards; thus, methods to reduce or eliminate fees for concussion resources should be explored to enhance their utilization. When considering how best to deliver staff education, schools should consider using interactive small

Table 2: Principals' challenges and suggestions for implementing concussion education and management procedures $(\mathbf{n}=39)$

\begin{tabular}{|c|c|}
\hline Challenges & Suggestions \\
\hline - Hard to reach parents & - 5-minute video to show parents at an information meeting \\
\hline - Need increased awareness and training for all stakeholders & - Posters or pages in student agendas \\
\hline - Lack of awareness of concussion education resources & - Central database to track concussions (similar to suspension incident reports) \\
\hline \multirow[t]{3}{*}{$\begin{array}{l}\text { - Need more specific guidelines to follow for delivering concussion education } \\
\text { and management protocols }\end{array}$} & $\begin{array}{l}\text { - Formalized protocol/procedure for delivering concussion education to all staff even if not involved } \\
\text { in physical/health education class }\end{array}$ \\
\hline & - Attach online resources to school website to increase awareness \\
\hline & - Mandatory training for all staff (schedule on Professional Development (PD) days to increase attendance) \\
\hline
\end{tabular}


group sessions that involve discussion and reflection on concussion incidents that have occurred in the school. Small group approaches have been shown to be very effective in knowledge transfer and may thus be of great benefit in the area of concussion education.

Parent concussion education was identified as the main area that required further development. This is consistent with previous evaluations of state concussion legislations where parent education was deficient. ${ }^{12}$ Difficulty in attracting parents to events or ensuring receipt of concussion-related documents were common issues reported by many principals. It is often only parents of concussed students who attend concussion-specific events, and, thus, strategies must be implemented to reach out to the entire parent population. Providing short, easy-to-read documents to parents about concussions may therefore be required for enhancing parent education. We acknowledge that timing may be a key determinant of whether parents receive or read these documents; thus, we suggest that concussion information be sent home at the start of each school year with accompanying registration forms because parent involvement and attention are often highest at this time. Furthermore, we recommend that parents be required to sign a document indicating that they are aware of the concussion issue before their child can participate in sports-related activities, as is done in some American states.

We identified several important findings in our analysis comparing school concussion policies before and after the PPM. Return to play and learn guidelines were significantly increased after introduction of the PPM. Although there was only a small increase in student education and staff training after the PPM, this is likely because pre-PPM implementation of these elements were already very high, thus making it hard to identify a large difference. Interestingly, parent education was previously very limited and has remained low even after the PPM. That principals indicated they still do not feel well-equipped to adequately deliver this aspect of their policy underscores the importance of investing additional resources in this area.

We focused on one school board in Ontario; however, schools within this board may not be reflective of all high schools in Ontario because of differences in resource access or location. In particular, the TDSB placed a heavy emphasis on concussion education many years before the PPM, which is reflected in the high pre-PPM implementation rates of concussion education. Furthermore, although the PPM applies to both elementary and high schools, we chose to focus our analysis on the latter because the incidence of concussions is highest among high school students. ${ }^{16}$ Future work is planned to expand analysis to elementary schools and also to include all boards across Ontario. Moreover, with any self-reported survey there is the potential for self-reporting bias in addition to response bias. To address these potential issues, we ensured all responses were anonymous and strongly encouraged principals to identify any problems or difficulties they experienced in implementing their policy in order to determine ways in which the board and ministry can provide further help.

Comparison of concussion policies pre- versus post-PPM was limited by the retrospective nature of the analysis because some respondents were unaware of specific components of their previous policy. We attempted to address this limitation by conducting additional sensitivity analyses. Furthermore, although we asked schools to compare their concussion policies pre- versus
post-PPM, it appeared that there was a delay in implementation of school policies because of the time required to fully implement various aspects of concussion education and training. Despite this, a very high proportion of schools had many aspects of a concussion policy in place as of January 30, 2015, and therefore these rates will likely further increase with complete implementation over the coming months. A subsequent survey is planned to evaluate the long-term result of PPM No. 158.

Based on the results of this study, we have made recommendations for all stakeholders involved in concussion education, management, and prevention, including schools, school boards, and agencies dedicated to injury prevention. Furthermore, these considerations should be taken into account by the education ministries in other provinces when concussion policies or legislations are being created.

\section{RECOMMENDATIONS}

1. Schools should have a formal database for tracking the incidence of student concussions.

2. All students should receive concussion education in school by a staff member who is trained in this area. Education may be provided in physical education classes, but measures should be taken to ensure that all students receive this education on entering high school with annual reminders thereafter.

3. All students and parents should receive information packages outlining the signs and symptoms of concussions, the principles of management, potential long-term consequences, and ways to prevent concussions. It is advised that these documents be distributed at the start of each school year along with the usual school registration forms.

4. All parents should sign a form stating that they have been educated on the risks of concussions in sports, ways to prevent concussions, along with the potential complications and postrecovery time.

5. All school concussion resources should be made available online for parents to access. This can be done through the school or board website.

6. There should be mandatory concussion training for all staff to understand the signs and symptoms of a concussion and the potential postrecovery time. This includes all teachers and administration staff.

7. Staff training should be delivered through a mixture of online training videos and in-person small group, interactive casebased sessions. Small group sessions should focus on discussing different concussion cases and brainstorming management approaches.

8. School principals or vice principals should be in charge of managing the return to learn protocol at each school.

9. Each school should establish a committee dedicated to maintaining their concussion policy and addressing ongoing concussion incidents or concerns that arise. This committee should include representation from the school principal or vice principal, coaches, teachers, and administration staff along with parent and student representatives. The committee should meet regularly to discuss concussion-related issues in the school along with any necessary changes that must be made to the school concussion policy.

10. Injury prevention organizations should aim to make concussion education and training resources available free 
of charge. This may be accomplished by obtaining sponsors for the resources.

\section{ConClusions}

This is the first examination of concussion education and management protocols in Canadian schools and the first evaluation of the process of implementing the Ontario PPM on concussions. Schools have significant student concussion education and return to play and learn guidelines. However, staff training and parent education require further development and may benefit from additional resources from the Ministry of Education and from agencies devoted to injury prevention. Findings from this study should aid schools, school boards, and injury prevention agencies in Ontario and elsewhere in further developing their concussion policies.

\section{ACKNOWLEDGEMENTS}

The authors thank the Determinants of Community Health II Course at the University of Toronto Faculty of Medicine for support in conducting this project.

\section{Disclosures}

The authors have nothing to disclose.

\section{SuPPlementary Materials}

For supplementary material/s referred to in this article, please visit http://dx.doi.org/10.1017/cjn.2016.41

\section{REFERENCES}

1. Thurman DJ, Branche CM, Sniezek JE. The epidemiology of sports-related traumatic brain injuries in the United States: recent developments. J Head Trauma Rehabil. 1998;13: 1-8.

2. Billette JM, Janz T. Injuries in Canada: insights from the Canadian Community Health Survey. Ottawa (ON): Statistics Canada; 2011. http://www.statcan.gc.ca/pub/82-624-x/2011001/article/11506eng.htm (accessed October 10, 2014).
3. Centers for Disease Control and Prevention. Nonfatal traumatic brain injuries from sports and recreation activities-United States, 2001-2005. MMWR Morb Mortal Wkly Rep. 2007;56:733-7.

4. Patel DR, Greydanus DE. Neurologic considerations for adolescent athletes. Adolesc Med. 2002;13:569-78.

5. Tator $\mathrm{CH}$. Concussions and their consequences: current diagnosis, management and prevention. CMAJ. 2013;185:975-9.

6. Tator CH. Sport concussion education and prevention. J Clin Sport Psychol. 2010;6:293-301.

7. Johnson LS. Return to play guidelines cannot solve the footballrelated concussion problem. J Sch Health. 2012;82:180-5.

8. Yard EE, Comstock RD. Compliance with return to play guidelines following concussion in US high school athletes, 2005-2008. Brain Inj. 2009;23:888-98.

9. Sady MD, Vaughan CG, Gioia GA. School and the concussed youth: recommendations for concussion education and management. Phys Med Rehabil Clin N Am. 2011;22:701-19.

10. Traumatic Brain Injury Legislation. Denver (CO): National Conference of State Legislatures; 2014. http://www.ncsl.org/ issues-research/health/traumatic-brain-injury-legislation.aspx (accessed November 13, 2014).

11. Engrossed House Bill 1824, Chapter 475, Laws of 2009, 61st Legislature, 2009 Regular Session, Youth Sports - Head Injury Policies, Effective Date: July 26, 2009. Washington State; 2009. ssl.csg.org/dockets/2011cycle/31B/31Bbills/0531b01bwayouth sportsheadinjurypolicies.pdf (accessed November 13, 2014 ).

12. Chrisman SP, Schiff MA, Chung SK, Herring SA, Rivara FP. Implementation of concussion legislation and extent of concussion education for athletes, parents, and coaches in Washington State. Am J Sports Med. 2014;42:1190-6.

13. Sawyer RJ, Hamdallah M, White D, Pruzan M, Mitchko J, Huitric M. High school coaches' assessments, intentions to use, and use of a concussion prevention toolkit: Centers for Disease Control and Prevention's heads up: concussion in high school sports. Health Promot Pract. 2010;11:34-43.

14. Esquivel A, Haque S, Keating P, Marsh S, Lemos S. Concussion management, education, and return-to-play policies in high schools: a survey of athletic directors, athletic trainers, and coaches. Sports Health. 2013;5:258-62.

15. Policy/Program Memorandum No. 158, School Board Policies on Concussion. Toronto (ON): Ontario Ministry of Education; 2014. http://www.edu.gov.on.ca/extra/eng/ppm/158.pdf (accessed November 13, 2014 ). Ontario Ministry of Education.

16. Macpherson A, Fridman L, Scolnik M, Corallo A, Guttmann A. A population-based study of paediatric emergency department and office visits for concussions from 2003 to 2010. Paediatr Child Health. 2014;19:543-6. 